\title{
PREPULSE INHIBITION LEVEL AS PREDICTOR OF MOTOR RESPONSE INDUCED BY COCAINE IN MALE AND FEMALE MICE
}

\author{
M.C. Arenas, M.D. Reguilón, E. Monzonís-López, J. Miñarro, C. Manzanedo \\ University of Valencia, Psychobiology, Valencia, Spain.
}

INTRODUCTION

\begin{abstract}
PPI is a measure of sensory-motor synchronization. A deficit in PPI may indicate alterations in the mesolimbic dopaminergic system. Recently, we demonstrated that the baseline PPI level of mice can predict their sensitivity to the reinforcing effects of cocaine. Mice with low PPI required a higher dose of cocaine to acquire the conditioned place preference, but they presented a more persistent associative effect of cocaine with environmental cues than high PPI mice. Behavioral sensitization after cocaine exposure is related to the transition from recreational use to the compulsive consumption of drugs.
\end{abstract}

\section{OBJECTIVE}

To establish whether prepulse inhibition (PPI) of the startle response can differentiate between subjects with a higher vulnerability to develop cocaine-induced locomotor sensitization.

\section{MATERIALS AND METHODS}

Female and male OF1 mice were distributed according to their high or low PPI levels. Afterwards, the locomotor response and locomotor sensitization induced by cocaine were assessed.

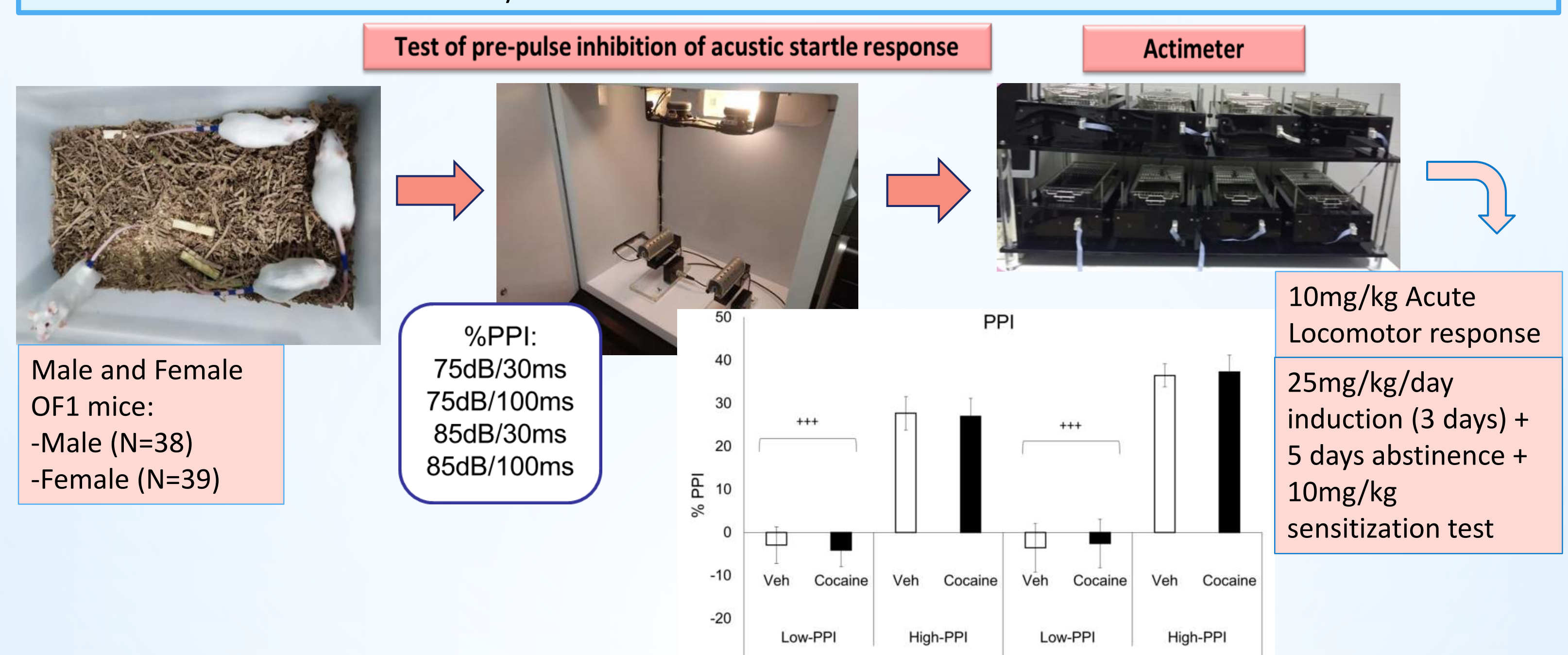

\section{RESULTS AND CONCLUSIONS}

Cocaine sensitization

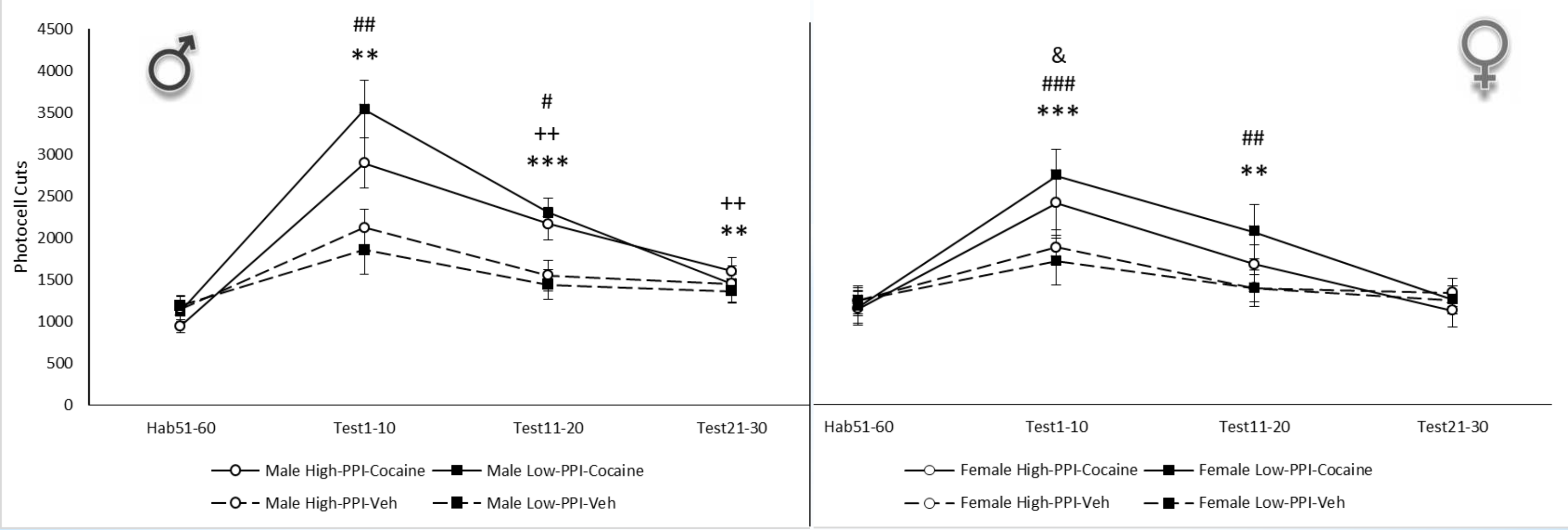

${ }^{* * *} p<0.001 ; * * p<0.01$ cocaine vs. saline in High PPI groups; ++p<0.01 cocaine vs. saline in Low PPI groups; \#\#\# $<0.001 ; \# \# p<0.01 ; \# p<0.05$ habituation vs. Test intervals in High PPI cocaine groups; $\& p<0.05$ habituation vs. Test intervals in Low PPI cocaine groups

Low-PPI mice showed lower hyperactivity induced by cocaine than High-PPI animals; however, Low-PPI mice pre-treated with cocaine displayed higher drug-induced hyperactivity than Low-PPI mice pretreated with saline and High-PPI animals pre-treated with cocaine. In conclusion, mice with low PPI presented a lower sensitivity to the motor effects of an acute dose of cocaine; however, they showed a higher and more perseverant locomotor sensitization induced by drug than animals with high PPI levels. Therefore, the PPI paradigm can detect the more vulnerable subjects to develop a cocaine use disorder. 